Revue

Revue de l'histoire des religions

de Ihistoire des religions

\title{
Jacques GÉLIS, Les enfants des limbes. Mort-nés et
} parents dans l'Europe chrétienne

s.l. [Paris], Audibert, 2006, 396 p. - [8 p. de pl.], 22 cm, $23 €$.

Albrecht Burkardt

\section{OpenEdition}

Journals

Édition électronique

URL : http://journals.openedition.org/rhr/7305

DOI : 10.4000/rhr.7305

ISSN : 2105-2573

Éditeur

Armand Colin

Édition imprimée

Date de publication : 1 décembre 2009

Pagination : 654-656

ISBN : 978-2200-92592-5

ISSN : 0035-1423

Référence électronique

Albrecht Burkardt, « Jacques géLıs, Les enfants des limbes. Mort-nés et parents dans l'Europe chrétienne », Revue de l'histoire des religions [En ligne], 4 | 2009, mis en ligne le 15 mars 2011, consulté le 22 septembre 2020. URL : http://journals.openedition.org/rhr/7305; DOI : https://doi.org/10.4000/rhr 7305

Ce document a été généré automatiquement le 22 septembre 2020.

Tous droits réservés 


\title{
Jacques GÉLIS, Les enfants des limbes. Mort-nés et parents dans l'Europe chrétienne
}

\author{
s.l. [Paris], Audibert, 2006, 396 p. - [8 p. de pl.], 22 cm, $23 €$.
}

\section{Albrecht Burkardt}

\section{RÉFÉRENCE}

Jacques GÉLIS, Les enfants des limbes. Mort-nés et parents dans l'Europe chrétienne, s.l. [Paris], Audibert, 2006, 396 p. - [8 p. de pl.], 22 cm, $23 €$.

1 Dès la fin du Moyen Âge, se répand en Occident la pratique du « répit »: le recours aux suffrages des saints pour obtenir, par un miracle, la résurrection momentanée d'un enfant mort-né rendant possible son baptême. C'est à ce type de culte, dont le dénominateur commun n'est pas le saint invoqué mais le motif d'invocation des fidèles, que Jacques Gélis consacre sa belle étude, prototype d'une enquête d'histoire religieuse menée à l'échelle européenne. Quatre champs d'observation, correspondant à autant de parties du livre, sont privilégiés: les mobiles des parents («Quand vient l'enfant mort ») ; la pratique du recours («Rites et dévotions ») ; les débats suscités par le répit («Un miracle qui divise »); les croyances de longue durée entourant le phénomène (« Des croyances enracinées »).

2 Les cultes considérés constituent l'exemple type d'une dévotion " populaire » qui se forme en réponse aux évolutions théologiques. La doctrine qui refuse le salut de l'âme aux enfants morts sans baptême (les limbes constituant le seul lieu possible de leur demeure dans l'au-delà,) se précise seulement au cours du bas Moyen Âge ; aussi, c'est parallèlement à ce développement que l'on assiste à une première diffusion de la pratique du répit. Le mouvement prend toute son ampleur dans les décennies qui suivent le concile de Trente : la décision qui rendait obligatoire le baptême dans un délai de trois jours, le contrôle accru de la pratique de l'ondoiement qui allait 
s'ensuivre inscrivaient encore plus dans les consciences l'impossibilité du salut de l'âme sans avoir bénéficié du sacrement qui était censé effacer le péché originel. En même temps, les taux de mortalité infantile, particulièrement élevés en proximité immédiate de la naissance, faisaient de l'enfant mort-né un cas de figure tout à fait fréquent, et rien ne permet de croire que la perte de ces êtres laissait indifférents les parents concernés. Les témoignages sont nombreux qui montrent le désespoir des proches confrontés non seulement à la mort physique de l'enfant mais aussi à sa condamnation à la souffrance éternelle, fait d'autant plus difficile à accepter qu'une telle mort pouvait s'interpréter comme un signe qui, tout en renvoyant aux péchés des parents, se voulait prémonitoire, « le fruit mort du couple annonçant le fruit mort de la terre ».

3 La pratique du répit offrait ainsi une échappatoire aux parents tourmentés, et elle se popularisait aisément dans le "climat miraculeux » de la Contre-Réforme. Cependant, malgré l'existence de légendes de saints morts-nés puis ressuscités, les recours considérés n'ont pas fait surgir une hagiographie propre; ils s'attachaient plutôt aux cultes de saints déjà établis dont certains se «spécialisaient " par la suite, comme à Sainte-Marie de Moustiers en Provence, à Moha en Belgique ou à Ursberg en Souabe, des hauts lieux du répit où tout était préparé pour recevoir les foules qui se recrutaient dans les couches sociales les plus diverses, dans un rayon d'attraction dépassant parfois nettement les limites de la fréquentation des sanctuaires à des fins thérapeutiques. La plupart de ces lieux étaient consacrés à la mère de Dieu : les corps des enfants, que les parents, dans bien des cas, n'avaient pas hésité à déterrer, étaient menés devant l'image ou la statue de la Vierge (et dans le cas d'autres cultes à proximité des reliques du saint vénéré), où les proches - dans la majorité des cas le père, parfois d'autres parents, moins souvent la mère (mais à laquelle revenait fréquemment l'initiative du départ) - attendaient ces curieux signes d'une résurrection momentanée qui, tout au moins lorsque ceux-ci duraient un certain temps et/ou que plusieurs d'entre eux apparaissaient conjointement, justifiaient le baptême sub conditione : un changement de couleur, de la sueur, la langue s'avançant sur les lèvres, de l'effusion de sang, l'apparence d'un mouvement. Signes que les dévots, notamment en hiver, l'été étant « la morte saison des répits » (p. 301), attendaient parfois pendant des semaines, même si, dans la plupart des cas, les miracles avaient tendance à apparaître plus tôt. Encore fallait-

il qu'ils apparaissent. À Ursberg, par exemple, les sources laissent entrevoir que les recours débouchant sur un répit n'ont guère dû dépasser les $10 \%$. Au XviII siècle, les délais d'attente pour l'obtention du miracle ont, de plus, eu tendance à s'allonger signe d'un soupçon accru des clercs.

Depuis le dernier tiers du XVII ${ }^{e}$ siècle, en effet, cette tendance commençait nettement à prendre le dessus dans le haut clergé, ce en tout cas en France, mais Rome suivait le pas dès le deuxième quart du siècle suivant. Plusieurs édits du Saint Office se prononçaient contre la pratique en question; en 1750, les miracles à Ursberg faisaient l'objet de toute une enquête inquisitoriale, et Benoît XIV l'interdisait en 1751. On se doute qu'un tel refus n'allait guère à l'encontre de l'esprit des Lumières naissant, encore que, curieusement, les théories médicales éclairées puissent parfois venir à l'appui de la possibilité du répit. Les principaux défenseurs des cultes, avant et souvent encore après l'interdiction, restaient toutefois bien des membres du bas clergé, plus à l'écoute des besoins des fidèles, et souvent eux-mêmes les promoteurs d'un sanctuaire accueillant les mort-nés. Mais les degrés d'adhésion variaient également selon les régions. Ainsi les autorités ecclésiastiques elles-mêmes avaient plus longtemps tendance à respecter, 
voire à défendre les cultes là où la Contre-Réforme restait vivace, notamment dans les zones de frontière de catholicité, les miracles au bénéfice des mort-nés constituant un atout propagandiste considérable de la reconquête catholique. Aussi l'interdiction de la pratique du répit ne menait-elle pas à sa disparition pure et simple. Les cultes avaient certes tendance à se marginaliser, soit en se situant dans la sphère privée (le « répit domestique »), soit en se déplaçant dans l'espace, des villes vers les campagnes et, audelà, vers des endroits de plus en plus reculés, vers des chapelles isolées en forêt, souvent desservies par des ermites.

Naturellement, ces évolutions ne se constatent que là où la pratique du répit ainsi que les croyances qui l'accompagnaient s'étaient pleinement établies. Or le trait sans doute le plus énigmatique qui caractérise les cultes en question réside dans le fait que ces derniers ne se sont pas diffusés dans toute l'Europe catholique. Ils trouvaient leur épicentre dans les Alpes et les régions limitrophes, depuis le sud de l'Allemagne jusqu'au sud-est de la France, en passant par le Jura et l'Alsace et en s'étendant de là vers le nord jusqu'aux Flandres espagnoles. En revanche, le sud-ouest de la France, la péninsule Ibérique, et l'Italie du sud ne semblent pas les avoir connus. Selon l'auteur, cette absence peut s'expliquer par l'existence de tout un ensemble de «rites de substitution ", tels le baptême "par l'Eucharistie » conféré aux futures mères ou, plus simplement, l'ensevelissement clandestin des mort-nés dans les églises ou cimetières dans l'espoir que la terre sacrée allait en quelque sorte effacer les effets négatifs du baptême manqué.

6 Sans doute faudrait-il aller plus loin dans l'analyse de ces « rituels de l'ombre », comme dans celles des origines médiévales de la pratique, probablement plus anciennes que ce que suggère l'auteur. De même, une approche plus attentive aux pratiques des dévots dans d'autres cultes de saints contemporains aurait permis de mieux saisir encore les particularités du répit. Éviter ces comparaisons pose en revanche problème : parfois, des phénomènes tout à fait dignes d'attention échappent ainsi aux analyses de l'auteur (les pratiques d'incubation auprès du lieu sacré, par exemple). De plus, l'interprétation des statistiques présentées est parfois compliquée par le fait qu'on ignore, pour un sanctuaire, s'il y a eu d'autres miraculés que ceux du répit, et si leur profil est le même. Ces remarques critiques n'enlèvent rien toutefois à la valeur des analyses conduites et à la richesse de la documentation livrée par l'auteur (le livre comprend aussi l'édition de nombreuses sources). Voici une étude désormais incontournable non seulement pour son sujet précis mais, bien au-delà, pour l'histoire culturelle de la première enfance, pour celle de la mort et des pratiques de dévotion. Une étude aussi qui s'inscrit de façon convaincante dans la lignée des conceptions de la «religion populaire » avancées par Alphonse Dupront, à la mémoire duquel le livre est dédié.

\section{AUTEURS}

\section{ALBRECHT BURKARDT}

Université Lumière Lyon 2. 